\title{
ENSINO DE TÉCNICAS DE COMUNICAÇÃO TERAPÊTTICA ENFERMEIRA-PACIENTE - REFERENCIAL TEÓRICO (Parte II)
}

Maguida Costa Stefanelli *

STEFANELLI, M.C. Ensino de técnicas de comunicação terapêutica enfermeira-paciente: referencial teórico - parte II. Rev. Esc. Enf. USP, São Paulo, 21(2): 107-115, ago. 1987.

Os conceitos aqui apresentados foram os que nortearam a pesquisadora no seu trabalho sobre ensino de técnicas de comunicação terapêutica no relacionamento enfermeira-paciente. São conceitos de estudiosos sobre teoria da comunicação humana, comunicação terapêutica e relacionamento interpessoal.

Após publicação da revisão de literatura sobre comunicação em enfermagem, em geral, e comunicação terapêutica (Parte I - STEFANELLI, 1986), é apresentado, nesta parte, o referencial teórico que subsidiou a pesquisa sobre ensino de comunicação terapêutica no relacionamento enfermeira-paciente.

UNITERMOS: Comunicação terapêutica. Relacionamento enfermeira-paciente.

Na tentativa de melhor compreender o processo de comunicação e de ajudar o homem a valer-se do mesmo, de modo mais útil, têm surgido vários estudos sobre teorias de comunicação e sobre relacionamento interpessoal.

Segundo LITTLEJOHN (1982), cada teoria estuda a comunicação por um prisma de especial interesse, mas o ideal seria que se fizesse uma abordagem eclética, estabelecendo uma complementação entre as teorias. Para o citado autor, a comunicação é um dos aspectos mais importantes e complexos do nosso comportamento, pois o ser humano é afetado pela própria comunicação que estabelece com os outros, a todo momento.

A importância da comunicação é ressaltada por PERESTRELLO (1982), quando afirma que a doença é um modo peculiar da pessoa se expressar em um dado momento de sua vida. Para o citado autor, a comunicação, mesmo quando o ser humano permanece em silêncio, é às vezes, mais significativa do que se as palavras estivessem presentes. Em seu livro percebe-se a importância da comunicação para humanização da medicina, a relação médico-paciente e o que ele chama de "medicina da pessoa".

O referencial teórico do presente trabalho é baseado nas teorias, princípios e conhecimentos de SULLIVAN (1953 a, b), o iniciador da

\footnotetext{
* Enfermeira. Professor Assistente Doutor do Departamento de Enfermagem Materno-Infantil e Psiquiátrica - disciplina Enfermagem Psiquiátrica.
} 
teoria interpessoal em psiquiatria; nos de RUESCH (1964) que estudou a teoria da comunicação humana e fez aplicações desta na área da psiquiatria; e nos de PEPLAU (1952), enfermeira introdutora do relacionamento terapêutico enfermeira-paciente na enfermagem. Os estudos posteriores que se seguiram sobre comunicação em psiquiatria ou em enfermagem psiquiátrica apoiaram-se, de um modo ou de outro, nos princípios destes autores. A seguir são apresentados alguns conceitos destes autores, relacionados à presente pesquisa.

\section{Conceitos da teoria de Hildegard Elizabeth Peplau}

Hildegarde E. Peplau, enfermeira formada em Pottstown, Pensilvânia, dedicou grande parte de sua vida profissional à enfermagem psiquiátrica. Seu livro "Interpersonal Relations in Nursing" publicado em 1952 é o relato de sua tese de doutoramento em Enfermagem Psiquiátrica.

PEPLAU (1952) considera a enfermagem como o relacionamento humano entre um indivíduo que está doente, ou necessitado de cuidado de saúde, e a enfermeira especialmente preparada para responder a esta necessidade de ajuda, necessidade que é satisfeita por meio de interações entre ambos - enfermeira e paciente - com objetivos comuns. Considera como elementos básicos ou variáveis, nas situações de enfermagem, as necessidades humanas básicas, a frustação, o conflito e a ansiedade, que devem ser tratados, no relacionamento enfermeira-paciente, de modo a favorecer o crescimento, ou seja, o desenvolvimento saudável da personalidade.

PEPLAU (1959, 1962) ressalta o subpapel de psicoterapeuta da enfermeira, pois considera que as dificuldades de vida que podem causar doença mental devem ser investigadas e controladas pelo próprio paciente com ajuda profissional da enfermeira. A ajuda a este é oferecida por meio do relacionamento terapêutico.

Este é desenvolvido, em grande parte, pelo uso de técnicas interpessoais úteis para situações especificas e que constituem o ponto crucial da enfermagem psiquiátrica - sua base.

PEPLAU (1968a) afirma ser o objetivo da enfermagem psiquiátrica ajudar o paciente a mover-se em direção ao pleno desenvolvimento de seu potencial para viver produtivamente na comunidade, este objetivo requer ações de enfermagem para ajudar o paciente a vencer os obstáculos que impedem o seu pleno desenvolvimento.

Tais obstáculos são agrupados em duas espécies: distúrbios do pensamento, sentimento e acões e distúrbios da competência interpessoal, essencial para a saudável interação social na comunidade. A citada autora apresenta algumas estratégias para ajudar o paciente, mas salienta que estas estavam, na época, apenas sendo desenvolvidas e que muito havia a ser feito.

Segundo PEPLAU (1970), em 1926 um eminente psiquiatra afirmou que as enfermeiras precisavam assegurar para si uma técnica es- 
pecífica; as enfermeiras têm, desde então, tentado defender, para si uma técnica - a comunicação verbal que ocorre entre elas e o paciente. A citada autora acredita ocorrerem manifestações de doença mental, mais acentuadamente no comportamento verbal do que nas ações propriamente ditas; considerada ainda, a comunicação enfermeira-paciente como um dos aspectos mais importantes da enfermagem; comenta que a enfermeira, ao falar com o paciente, pode fazê-lo de modo espontâneo, estereotipado ou automático, modos que servem mais ao propósito simplesmente de falar alguma coisa do que ao de dizer algo específico ou significativo para o mesmo. Pode, ainda, fazer um comentário baseado em princípios e conceitos teóricos e gerais, que facilitam a compreensão do que o paciente está dizendo e a orienta sobre que resposta dar ao paciente.

Estes conceitos e princípios devem ser estudados e firmados com profundidade, de modo a oferecer fundamentos lógicos para o uso de técnicas de comunicação interpessoal, que são a base do comportamento consciente por parte da enfermeira. Ela tem de familiarizar-se com as técnicas interpessoais de comunicação para validá-las na prática e decidir em que situações cada procedimento será mais útil.

\section{Conceitos da teoria de Harry Stack Sullivan}

Harry Stack Sullivan tem várias obras publicadas. As que serviram de base para este estudo foram "The interpersonal theory of psychiatry", "Conceptions of modern psychiatry" e "Psychiatric interview" (SULLIVAN $1953 a, 1953 b$ e 1970).

O pensamento de Sullivan foi voltado para o desenvolvimento de uma terapia efetiva, e não para um sistema teórico de alta ordem de abstração; para ele o "eu" não é um fato, mas um ato. A pessoa é o resultado de um processo social decorrente da experiência com outras pessoas, desde o nascimento até a morte; a Psiquiatria, portanto, não pode estudar o ser humano isoladamente, e sim inserido em suas experiências interpessoais, tendo como foco o desenvolvimento da pessoa e a satisfação da necessidade de segurança. Concluindo, a definição de pessoa só é possivel em face de outra pessoa.

A experiência para Sullivan é sempre de tensão e de transformação de energia e se manifesta de três formas distintas: prototáxica, paratáxica e sintáxica.

A prototáxica é a primeira classe de experiência que tem o ser humano; nesta, só o presente importa, não havendo relação alguma da experiência com o espaço e o tempo.

Com o desenvolvimento, a criança começa a fazer alguma diferenciação entre ela e o resto do mundo; já faz alguma diferenciação no todo, mas as partes, os diversos aspectos, as várias espécies de experiências não se apresentam relacionados de modo lógico; ela apenas vivencia 
experiências concomitantes. A comunicação se dá por gestos e símbolos, principalmente pelos canais visual e auditivo: é a forma paratáxica.

A forma sintáxica de experimentar a realidade se dá quando as percepções da pessoa formam um todo lógico, um quadro coerente, que pode ser validado consensualmente pelo uso da linguagem; recorda as experiências passadas, avalia como estas influem no presente e é capaz de prever as conseqüências da ação presente no futuro.

Sullivan cita três aspectos da cooperação interpessoal do sistema do eu ("self") que são necessários para a sobrevivência da criança e ditam a aprendizagem da mesma; chama a estes aspectos de "eu-bom", "eu-mau" e "não-eu". O "eu bom" é formado a partir da obtenção de aprovação, manifestada por ternura pela figura materna, às tentativas que a criança faz para aliviar a ansiedade e obter satisfação de suas necessidades, principalmente da de segurança, no meio social. Quando a criança manifesta comportamento que provoca desaprovação, por parte da mãe ou de pessoa significativa, experimenta ansiedade em vários graus e tem origem a formaçāo do "eu mau". O "não eu" surge das experiências que geram muita ansiedade, ou mesmo pânico; são, geralmente, experiências truncadas, não claramente conhecidas, podendo ser dissociadas; em geral permanecem em nivel inconsciente e nó afloram à consciência da pessoa em situaçōes especiais, como durante a psicoterapia, ou em sonhos; são também, encontradas em pessoas com manifestações agudas de esquizofrenia; se este material inconsciente aflora à consciência traz experiências de ansiedade terrificante.

Os estágios de desenvolvimento começam na infância e se desenvolvem de modo ordenado, refletindo mudanças na experiência interpessoal do individuo.

O foco da terapia baseada na teoria de Sullivan é a ansiedade, uma vez que esta tem papel preponderante no desenvolvimento da personalidade e surge sempre que a satisfação das necessidades básicas é ameaçada. A ansiedade gera desconforto e a pessoa tenta livrar-se dela ou evitá-la; quando surge em grau intenso, dificulta o relacionamento interpessoal ou o uso de padrões habituais de comunicação, dai a importância do terapeuta ouvir a descrição da experiência do paciente, como este a experimenta e a sente.

Ao ouvir a descrição da experiência do paciente, o terapeuta esforça-se por perceber os aspectos que provocam sua ansiedade e tenta compreendê-lo, o melhor possivel, pela validação consensual da experiência.

$O$ descrever da experiência leva o paciente a perceber seus sentimentos em relação à situação descrita, o que a mesma significa para ele e os eventos que a precederam. Para Sullivan, isto facilita qualquer processo terapêutico, porque o paciente começa a compreender o que está acontecendo com ele e torna-se capaz de encarar mais objetivamente suas dificuldades, seus pensamentos e sentimentos, tais como os percebe; consegue, assim, aliviar sua ansiedade e satisfazer sua necessidade de segurança. 
Como Sullivan acredita que a doença mental é resultante de falha no processo interpessoal ou de comunicação inadequada da pessoa com os outros, um aspecto relevante de sua teoria é a sua crença no potencial do indivíduo para mudança e na adaptabilidade do ser humano para responder a pessoas e à cultura; para ele, portanto, o comportamento anormal é passivel de observação, diagnóstico e tratamento por meio do relacionamento interpessoal.

\section{Conceitos das teorias de Jurgen Ruesch.}

Os princípios de comunicação humana e da comunicação terapêutica de Ruesch e a aplicação destes à Psiquiatria tiveram influência decisiva

nas abordagens psicoterapêuticas (RUESCH, 1952, 1953, 1954, 1957, $1964,1965,1980)$, e, conseqüentemente, também, no desenvolvimento da teoria e prática do relacionamento terapêutico enfermeira-paciente.

No presente trabalho, nos deteremos apenas nos aspectos de comunicação verbal da teoria de Ruesch.

Ruesch considera a comunicação o princípio organizador da natureza que une um ser ao outro; para ele, comunicação abrange todos os modos pelos quais uma pessoa pode afetar outra, de modo verbal e não verbal. Todas as ações de um indivíduo adquirem poder de comunicação tão logo sejam percebidas pelo outro; isto implica em mudança das informações em mensagens, que uma pessoa (B) recebe da outra (A) e do ambiente; a informação da percepção pelo outro (B), de seu comportamento é a resposta para ele (A) e influencia seu comportamento subseqüente (de A). Assim, Ruesch concluiu que o sucesso na comunicação interpessoal é necessário à sobrevivência da pessoa.

Os elementos que compõem o sistema de comunicação são a fonte da mensagem (em geral um ser humano), o transmissor, o canal, o receptor (órgãos dos sentidos) e o destinatário (outro ser humano que interpreta e avalia a mensagem).

Algumas das premissas básicas da teoria de RUESCH $(1964,1965)$ são descritas a seguir.

A unidade de trabalho é a unidade social; esta unidade social ocorre quando a pessoa se encontra em processo interpessoal; a comunicação interpessoal caracteriza-se pela presença de atos expressivos de uma ou mais pessoas, pela percepção consciente ou inconsciente destes atos, por outra pessoa, e pela observação de que tais atos foram percebidos pela outra. A consciência de ser percebida é que marca o estabelecimento da situação interpessoal.

Além da comunicação interpessoal existe a intrapessoal que afeta a comunicação interpessoal. As experiências passadas que se organizam dentro do indivíduo em idéias, sentimentos e fantasias representam, dentro dele, pessoas presentes ou ausentes. Há, entretanto, uma diferença básica entre esta e a interpessoal; na interpessoal os efeitos das ações podem 
ser avaliados e corrigidos; na intrapessoal torna-se difícil perceber a interpretação inadequada das mensagens.

O aparelho da comunicação do homem é algo mais que a sua simples localização anatômica. A comunicação tem de ser vista como uma entidade funcional e não apenas como um conglomerado de órgãos.

Ruesch considera, também, como parte do instrumento de comunicação, o aparelho avaliador que inclui as funções de escrutínio, memória e tomada de decisões.

As limitações da comunicação são determinadas pela capacidade da rede intrapessoal, seletividade dos receptores e capacidade dos transmissores. Outro aspecto a ser considerado é a dificuldade em analisar a significação das mensagens. Esta análise é de suma importância na assistência à pessoa mentalmente perturbada pois a linguagem empregada por terapeuta e paciente deve ter a mesma significação para ambos.

E por meio da comunicação que um ser humano se mantém em interação com outro, evitando assim a solidão; são, pois, funções da comunicação: receber, transmitir e reter informação, reconstruir o passado, antecipar fatos futuros e trabalhar com a informação existente, com o propósito de perceber novos elementos para exercer influência sobre outras pessoas e sobre acontecimentos externos.

Quanto aos efeitos da comunicação, Ruesch considera que esta facilita ou promove o desenvolvimento e amadurecimento do indivíduo.

Qualquer interferência nos padrões habituais de comportamento da pessoa leva a uma reação de alarme que, se não for controlada, gera ansiedade. O meio para torná-la tolerável é partilhá-la com outros por meio da comunicação.

Para Ruesch a comunicação bem sucedida implica em sermos cor. rigidos por nós mesmos ou pelos outros. Este processo contínuo de atualização da informação sobre a pessoa, o mundo e a interrelação entre eles leva a pessoa a aprender técnicas apropriadas de comunicação e pode aumentar a capacidade do indivíduo para controlar fatos vitais. Neste caso, a comunicação bem sucedida é sinônimo de adaptação e vida.

Os distúrbios na comunicação podem dar-se nos níveis orgânico, intrapessoal ou interpessoal. Para descrever os distúrbios da comunicação temos de considerar seus vários aspectos: a) um aspecto técnico (instrumentos de comunicação), b) um aspecto semântico (precisão com que a série de símbolos transmitem o sentido desejado da mensagem, incluindo as distorções semânticas), e c) um aspecto de interação (efeitos que a transmissão de informação tem sobre a conduta da pessoa, ao se tentar atingir um efeito desejado).

Para terminar a descrição das premissas de Ruesch, são apresentados seus conceitos de doença mental, terapia psiquiátrica e comunicação terapêutica. 
A doença mental é vista pelo autor como um distúrbio no sistema de comunicação. Valida sua afirmação apoiando-se no fato de que a manifestação da doença mental é sempre descrita em termos de comportamento comunicativo e que o denominador comum de todo método psicoterápico é uma tentativa de tornar adequada a comunicação perturbada. A comunicação torna-se, então, um instrumento terapêutico e é aceita por ele, como psicoterapia, uma vez que a preocupação do psicoterapeuta é com o aspecto funcional da comunicação.

A terapia psiquiátrica tem por objetivo o aprimoramento e a recuperação do sistema de comunicação, ou a correção do distúrbio da comunicação atuando nos aspectos semântico ou de interação. Quando se consegue obter a melhora na comunicação do cliente consigo mesmo e com os outros, a correção e a auto-correção da informação provêem as bases para a sua mudança de conduta.

Comunicação terapêutica é a habilidade do profissional em ajudar as pessoas a enfrentarem tensão temporária, a conviver com outras pessoas, a ajustar-se ao que não pode ser mudado e a enfrentar os bloqueios à auto-realização.

Esta ajuda se consegue pela utilização do que Ruesch chamou inicialmente de terapia para aliviar a reação de alarme. Isto é possível por meio de interações com o terapeuta ou com outra pessoa capaz de controlar a própria ansiedade: a pessoa aprende a trabalhar dentro de seus próprios lumites de tolerância, evitando atos impulsivos e a recorrência de adiamentos de tomadas de decisões, indefinidamente. Consegue, assim, coordenar ações com palavras, pensamentos e sentimentos.

Pela descrição de suas experiências de vida diária, o paciente torna-se familiar com o fato de que a ação é o dado de base sobre o qual o comportamento humano, a mútua compreensão e a comunicação são edificados; deve, então, aceitar a seqüência: ação-percepção-codificação-expressão. Quando isto é estabelecido podemos dizer que a comunicação foi bem sucedida.

As características básicas da comunicação bem sucedida são flexibilidade, eficiência, propriedade e resposta.

A flexibilidade requer do terapeuta, habilidade em estabelecer novos objetos para a satisfação de necessidades emergentes em cada situação; ele tem de considerar que cada pessoa é única e está constantemente em processo de mudança; ser flexível não é tarefa fácil, pois requer abandono de objetivos planejados e elaboração de novos e, muitas vezes, em tempo escasso.

Para que a eficiência esteja presente na comunicação é necessário que as mensagens enviadas tenham clareza, simplicidade e sejam transmitidas quando o receptor está apto para ouvir; a eficiência elimina jargôes hospitalares, linguagem rebuscada e ambigüidade.

A fim de que a mensagem tenha propriedade, ela deve ser relevante para a situação em que se encontram terapeuta e cliente; tem de res- 
ponder à mensagem do paciente como um todo de modo coerente, sem menosprezar ou supervalorizar uma ou outra parte.

Ruesch dá o nome de "resposta" ao processo de observação do efeito da mensagem e correção da informação. A resposta tem função reguladora da comunicação, e informa o outro sobre o impacto de sua própria comunicação. A resposta provê a pessoa de um modelo de informação que é a base para a tomada de decisão e controle da ação. A personalidade é o resultado de dotação genética, modificada pela ação da comunicação desenvolvida com outras pessoas e que terminam por conduzir as ações de vida diária.

O processo terapêutico é visto, então, como um intercâmbio interpessoal de mensagens, que exerce influência corretiva sobre os participantes da situação interpessoal. A observação de tais efeitos e a correção da informação inicial são chamadas "resposta". A pessoa mentalmente sadia adquire habilidade em corrigir informação errônea, ou seja, melhorar seu próprio desempenho; a pessoa mentalmente doente perde esta capacidade, cuja recuperação depende das respostas corretivas que venha a receber de outras pessoas. O paciente recupera-se quando readquire a capacidade de se comunicar livremente e quando seu corpo de informações corresponde aos eventos que estão ocorrendo. Informação correta é, portanto, a chave que abre as portas para a saúde mental.

Para Ruesch a comunicação com efeito terapêutico não deve ser limitada apenas a psicoterapeutas; ela deve abranger os processos educacionais, de aconselhamento em geral e mesmo os relacionamentos de amizade. $O$ autor afirma que muitas pessoas usam a comunicação de modo terapêutico sem perceber que o fazem. Os profissionais da área de saúde, entretanto, têm o dever e a responsabilidade de se esforçar para tornar terapêutica a comunicação com o cliente.

Pode-se concluir que para Ruesch:

- a comunicação é o componente central da saúde mental;

- as perturbações mentais só podem ser percebidas pela comunicação do paciente com os demais;

- todo tratamento psiquiátrico deve ter como objetivo central o restabelecimento da comunicação efetiva (correção da informação).

Pelos conceitos expostos no referencial teórico fica evidente a importância de cada enfermeira envidar esforços para se comunicar terapeuticamente com o paciente, tornando cada uma de suas ações a mais efetiva possivel.

Como cada momento é único e não se repete, tendo em vista as peculiaridades pessoais, de tempo e de espaço e que a saúde mental está diretamente relacionada com a comunicação interpessoal, a enfermeira tem de tornar cada palavra, cada ação, cada gesto, em suma, sua comunicação em um momento terapêutico. 
STEFANELLI, M.C. Teaching communication therapeutic techniques in nurse-patient relationship: conceptual basis - Part II. Rev. Esc. Enf. USP, São Paulo, 21(2): 107-115, Aug. 1987.

The conceptual basis used in this research are presented in this papers. The author presents the basis concepts underlying human communication theory, therapeutic communication and interpersonal relationship.

UNITERMS: Therapeutic communication. Nurse-patient Relationship.

\section{REFERENCIAS BIBLIOGRAFICAS}

LITTLEJOHN, S.W. Fundamentos teóricos da comunicacão humana. Rio de Janeiro, Zahar, 1982. $407 \mathrm{p}$.

PEPLAU, H.E. Interpersonal relations in nursing. New York, G.P. Putnam's, $1952.330 \mathrm{p}$.

- Principles of psychiatric nursing. In: ARIETI, S. American handbook of psychiatry. New York, Basic Books, 1959. cap. 92, p.1840-56.

Talking with patients. Amor. J. Nurs., New York, 60(7):964-6, July, 1960.

- Interpersonal techniques: the crux of psychiatric nursing. Amor. J. Nurs., New York, 62(6):50-4, June, 1962.

Nov./Dec. 1968(a).

- Princípios básicos para orientación del paciente. Washington, Organização Panamericana da Saúde, 1968. 60p.(b).

. Foreword. In: HAYS, J.S. \& LARSON, $K$. Interacting with patients. New York, Mac Millan, 1970. p. vil-x.

Perestrello, D. A medicina da pessoa. Rio de Janeiro, Atheneu, $1982.244 p$.

RUESCH, J. The therapeutic process from the point of view of communication theory. Amer. J. Orthopsychiatry, New York, 22(4):690-700, July. 1952.

215-43, 1953.

$1-18,1954$.

. Disturbed communication. New York, Norton, 1957. 337p.

- Comunicación terapéutica. Buenos Aires, Paidós, 1964. 339p.

- Valores, comunicación y cultura. In: RUESCH, J. \& BATESON, G. Comunicación:

la matrix social de Ia psiauiatria. Buenos Aires, Paidos, 1965 . p.9-23.

Communication and psychiatry. In: KAPLAN, H.I. et alii. Comprehensiv
of psychiatry III. 3. ed. Baltimore, Williams \& Wilkins, 1980 . cap.4, p.443-58.

STEFANELLI, M.C. Ensino de técnicas de comunicação terapêutica enfermeira-paciente: parte I. Rev. Esc. Ent. USP, Săo Paulo, 20(2):161-183, ago., 1986.

SULLIVAN, H.S. The interpersonal theory of psychiatry. New York, Norton, 1953. 393p.(a) Conceptions of modern psychiatry. New York, W.W. Norton, 1953. 298p.(b)

—_. The psxchiatric interview. New York, Norton, 1970. 246p.

Recebldo para publicação em 2/9/86.

Aprovado para publicação em $20 / 7 / 87$

Rev. Esc. Enf. USP, São Paulo, 21(2):107-115, ago. 1987 